\title{
Problem-Solving Skills as A Mediator Variable in the Relationship between Habits of Mind and Psychological Hardiness of University Students
}

\author{
Mohamed Sayed Abdellatif ${ }^{1,2}$ \& Mervat Azmi Zaki ${ }^{3,4}$ \\ ${ }^{1}$ Department of Educational Sciences, Faculty of Education, Prince Sattam Bin Abdulaziz University, Kingdom of \\ Saudi Arabia \\ 2 Department of Educational Psychology, Faculty of Education in Assiut, Al-Azhar University, Egypt \\ ${ }^{3}$ Department of Special Education, Faculty of Education, Prince Sattam Bin Abdulaziz University, Kingdom of Saudi \\ Arabia \\ ${ }^{4}$ Department of Mental Health, Faculty of Education, Minia University, Egypt \\ Correspondence: Mohamed Sayed Abdellatif, Faculty of Education in Wadi Addawasir, Prince Sattam Bin Abdulaziz \\ University, BO Box 54, Wadi Addawasir 11991, Saudi Arabia.
}

Received: October 18, 2020

Accepted: December 23, 2020

Online Published: December 24, 2020

doi:10.5430/ijhe.v10n3p88

URL: https://doi.org/10.5430/ijhe.v10n3p88

\begin{abstract}
This study investigated the role of problem-solving skills as a mediator variable in the relationships between habits of mind and the psychological hardiness among university students, and to identify the difference between male and female students in each of the habits of mind, psychological hardiness, and problem-solving skills. The sample comprised of 285 male and female, third-year Faculty of Education, University students. The data collection utilized the habits of mind scale, the problem-solving scale, and the psychological hardiness scale (Mekhemer, 1996). SPSS v. 25 and AMOS v. 24 were used to process data. The findings revealed that problem-solving skills partially mediates the relationship between habits of mind and psychological hardiness, and the results also demonstrated that there are no statistically significant differences between male and female students in habits of mind, problem-solving skills, and psychological hardiness. Future research suggestions include planning stakeholders at the university stage should take into consideration the necessity to integrate habits of mind and problem-solving skills in curricula, and providing training for faculty members to enhance university students' psychological hardiness.
\end{abstract}

Keywords: habits of mind, problem-solving skills, psychological hardiness, mediator variable

\section{Introduction}

The University stage is one of the most crucial stages that may affect a student's future quality of life (REF), as they are exposed to many issues and life pressures that may negatively influence their professional and social futures. In response, it is important to examine university students' personal, social and academic profiles, and empower them with experiences and skills which may better equip them to face the academic challenges, setbacks, pressures, and to train them to creatively solve their problems and to negotiate their tertiary context.

Psychological hardiness is one of the major fields in positive psychology, which maximizes human forces as a genuine force in man because it aims to achieve the quality of life (Kobasa, Maddi, Paccetti, \& Zola, 1985, Muhammad, 2015). Psychological hardiness refers to an individual's ability to challenge, commit and control stressful life situations and frustrations depending on his previous experiences, by using their psychological, environmental, and social capabilities, to successfully achieve their goals (Al-Hadari, 2018).

Individuals exhibiting high levels of psychological hardiness are typically courageous, optimistic, and resilience. They endeavor competition and challenge to achieve success (Bartone, 2007; El Jalba, Soliman \& Yousef, 2018; Taylor, 1995). Individuals with high psychological hardiness are also motivated to pursue effective problem-solving skills during stressful situations, and they rate stressful conditions as more difficult, controllable, and less threatening (Abdollahi, Talib, Yaacob, \& Ismail 2015; Delahaij, Gaillard, \& van Dam, 2010). The literature supports that psychological hardiness reduces nervousness and anxiety, and is positively associated with mental alertness, adjustment, as well as emotional and mental health (Tatari, 2020; Amlakian et al., 2020; Maddi, 1999; Maddi, 2006). 
It also contributes to the development of psychological well-being (REF). For example, a study by Amlakian, Amiri, and Taheri (2020) reported that psychological hardiness mediated the relationship between psychological well-being and religious commitment among university students. Additionally, research by Tatari (2020) indicated that psychological hardiness represented a preventative factor against drug addiction and suicidal thinking.

Psychological hardiness comprises three dimensions: commitment, control, and challenge. 'Commitment' is defined as the general sense of purpose and interest in life (Eid, 2002). The 'control' dimension refers to the belief in the individual's capacity to impact circumstances and taking responsibility for the events that they are exposed to (Abbas, 2010), and the 'challenge' dimension incorporates considering new events and challenges as an opportunity for personal growth (Kobasa et al., 1985). This research adopted Mukhaimer's (1996) definition of psychological hardiness "a psychological contract the person commits towards himself, his goals, his values, and the others" (Mukhaimer's, 1996, 201)This definition indicates an individuals' belief that they can manage the events they experienced, and take responsibility for them as they admit that the changes in their life are vital for their growth, rather than considering it as a threat or disability. Participants' psychological hardiness is measured in this research by the results students obtained on the psychological hardiness scale within its three dimensions: commitment, control, and challenge.

Problem-solving skills represent an essential prerequisite of an individual's life, as many situations they faced daily are predominantly situations that require solutions. Problem-solving skills reflect one of the most complex and important forms of human behaviors that students must learn, with the aim of being able to make sound decisions in their lives (Al-Quraishi, 2014). Various definitions of 'problem-solving skills' can be found in literature: Some studies define problem-solving skills as a cognitive-behavioral process through which the individual tries to determine and discover effective means to deal with the problems encountered in daily life (Cormier et al., 2009). Others defined 'problem-solving skills' as the ability to drive results from given premises, and a type of performance that enables the individual to reach the unknown facts they want to discover through understanding causes and factors involved in this problem (Al-Adl and Abdel Wahab, 2003). Al-Ayasrah (2015) refers to 'problem-solving skills' as a set of processes an individual performs using previously learned knowledge and skills acquired in overcoming the new situations in a new and unfamiliar manner. For the purpose of this article, "problem-solving skills' is a mental activity that includes a set of operations carried out by students starting with the individual's ability to define goals, using previous knowledge and skills, and employing the good experiences of others to achieve his goals. The three Emuford problem-solving skills (Emuford, 2002) were adapted for the research because - you need to put in an explanation here - and are as follows: i) the ability that implies the individual's possession of knowledge; ii) the ability to research the desired goals and efficiency that reflects the methods used by the individual to try to solve a problem; iii) and the ability to try to cooperate effectively and productively with various groups to achieve goals.

Numerous studies agreed upon the significance of problem-solving skills as they contribute to motivating students to build their own experiences so that they don't appeal to receive knowledge from anyone and play a positive and effective role in all stages of the problem-solving process (Al-Quraishi, 2014; Karaki and Al-Awada, 2020; Muslim, 1993; Virginia, 2015; Zaitoun, 2003). Problem-solving skills raise the learners' motivations to learn enjoy working on the problem formulated by themselves and feel its' existence and the need to solve it because it challenges their knowledge. Moreover, these skills push students to develop their professional information and capabilities, to build their own experiences, develop team skills, and skills to apply specific theories and concepts. Problem-solving skills allow for creativity, innovation, and initiation in any challenging situation especially when the problems are real and related to students' lives and society (Al-Fastala and Abu Asaad, 2015; Al-Helou, 2001; Al-Quraishi, 2014; BİLGİÇ, 2018; Cormier et al., 2009).

Recently a trend in American educational ideology called upon educators to focus on achieving several educational outcomes related to thinking skills and problem-solving and focused on the necessity of developing thinking strategies in what has become known as 'habits of mind approach' or theory (Al-Harthi, 2002). This approach emphasizes the necessity to prepare and instill creative, critical, and effective thinking methods and skills amongst students, so they can train themselves in the 'habits of mind' that enables them to solve and address future problems on their own, and focuses on how information is acquired to address the outcomes of the modern era and its rapid changes (Costa and Kallick, 2009). Habits of mind theory represent important variables related to the academic performance of learners at different educational stages in general, particularly at the university stage.

To study and explain habits of mind that students use when undertaking their daily activities, several models and theories emerged, including Daniel's perspective (Daniels, 1994) who represents four components of habits of mind 
as follows (i) The open-mind which is considered a distinct personality features that affect their actions and orientations. This individual is characterized by a strong and vivid personality, and have the ability to communicate with and help others, displays intuitive speed, are multidisciplinary in their ideas and answers, have the ability to analyze, synthesize and evaluate, has the ability to use evidence in making decisions, searches for relationships, and puts forward different alternatives to solve problems; (ii) the fair-Minded indicates the balance between all ideas and solutions of different situations. Those individuals are rational, objective, open-minded, reasonable, even-handed, have sound judgment, respect rules, are contributors and deserving, build sound relationships, and are selfless; (iii)The independent-minded refers to the ability to equally address all points of views, and demonstrate an honest and fair way of thinking. These individuals are characterized by realism, interested with detail based on discovering, adapting opinions that are logical and they are more effective in problem; and (iv) the inquiry or critical attitude that has the ability to effectively critique ideas and opinions, and identify their strengths and weakness in order to evaluate them, and reach the best solution to problems faced. This component has five essential components- none of them is are indispensable - the knowledge base, the personal theory, external events, feeling of contradictions or divergence, and the solution of the contradictions.

\subsection{The Relationship between Habits of Mind, Problem-Solving Skills, and Psychological Hardiness:}

The logical relationship between habits of mind and problem-solving various skills is clear according to Daniels' (1994) theory. Logically, habits of mind provide the fuel of thinking, as students who possess high habits of mind use essential and creative thinking together to solve problems. Moreover, habits of mind are associated with flexibility, openness, independence, mental justice, the ability to criticize and seek solutions to many dilemmas facing individuals. In this context, Gail (2006) notes that habits of mind represent a pattern of intelligent behaviors that lead the learner to actions that are formed as a result of responses to certain types of problems, provided that solutions to such problems require thinking, research, and reflection (Gail, 2006). According to Daniel's (1994) perspective, habits of mind corresponds to the characteristics of students with high psychological hardiness, and this is what underpins the relationships between habits of mind, and the ability to cope with stressful situations (Al-Fastala and Abu Asaad, 2015; Amin and Gaber, 2018; Kleinsteuber, 2014; Taylor, 1995; Van and Bos 2006; Al-Fastala and Abu Asaad, 2015). In addition, Karaki and Al-Awada (2020) concluded that people with habits of mind are distinguished by emotional balance and the ability to make appropriate solutions to problems.

Many studies conclude that psychological hardiness is related to problem-solving, and that those with high psychological hardiness have the attitude to pursue effective problem-solving skills during difficult situations, as they believe they have to control it and that it is less threatening (Abdollahi et al., 2015; Bansal's, 2014; De, Raad \& Perugini, 2002). Maddi $(1999 ; 2006)$ reported that those with high psychological hardiness are distinguished by serious planning, challenging obstacles, and the ability to solve problems effectively. Other researchers revealed that psychological hardiness mediates the relationship between problem-solving skills and suicidal thinking (Hosseinian \& Beh-Pajooh, 2018) and that those with high psychological hardiness can create many alternatives to solve problems, persist and challenge (Taylor, 1995 \& Van, 2006). Further, studies demonstrated also the relationship between habits of mind and the ability to cope with stressful situations (Amin \& Gaber, 2018).

Through reviewing the literature, the researchers demonstrated that there is no theoretical model that combines habits of mind, problem-solving skills, and psychological hardiness, despite the results of previous studies confirm the existence of such relationships between these variables. This study sought to reveal the best casual model that shows the direct and indirect effects of the research variables habits of mind and problem-solving skills, and their dimensions on the psychological hardiness among university students.

\subsection{Research Model and Theoretical Reasoning for It}

The theoretical model included the following variables: The independent or predictive variable habits of mind, the mediating variable: problem-solving skills, and the dependent variable: psychological hardiness. Based on the theoretical framework and reviewing previous research, a proposed theoretical model was developed that assumes that habits of the mind have a direct positive effect on problem-solving skills and that habits of the mind and their components also affect positively, indirectly, on psychological toughness through problem-solving skills, in addition to the hypothesis that problem-solving skills have a direct positive impact on psychological hardness as shown in figure 1 . 


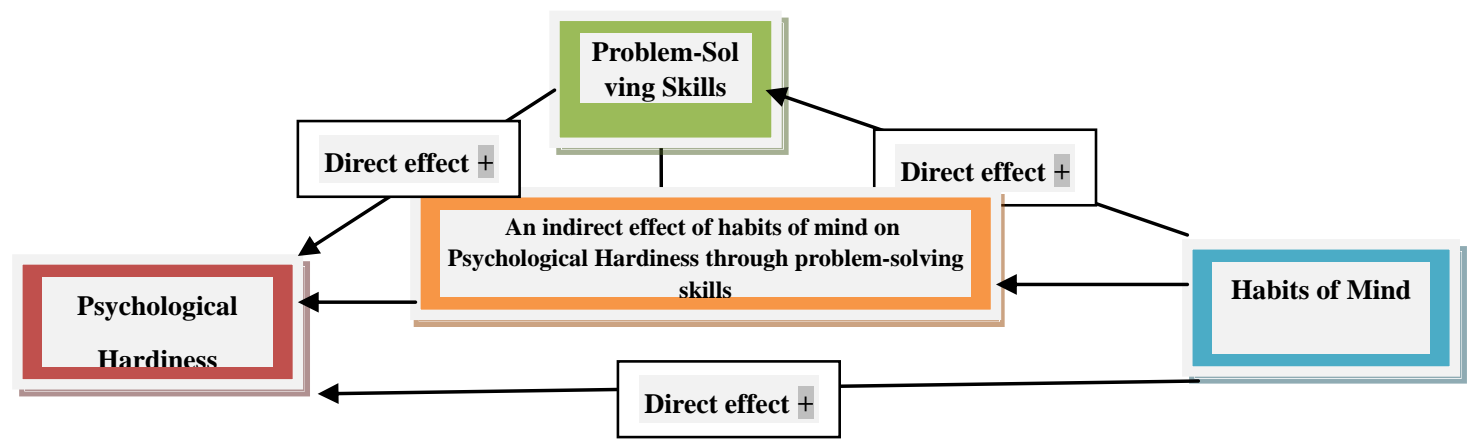

Figure 1. the proposed model for problem-solving skills as a mediator variable between habits of mind and psychological hardiness

\subsection{The Following Hypotheses are Investigated}

Hypothesis 1 (H1). There is a fit of the proposed structural model for problem-solving skills as a mediator variable between habits of mind as an independent variable, and psychological hardiness as a dependent variable among university students. This hypothesis contains the following sub-hypotheses:

a) There is a direct statistically significant effect of habits of mind on psychological hardiness among university students.

b) There is an indirect statistically significant effect of habits of mind on psychological hardiness through problem-solving skills as a mediator variable for university students.

c) There is a direct statistically significant effect of habits of mind on university students' problem-solving skills.

d) There is a direct statistically significant effect of problem-solving skills on psychological hardiness among university students.

Hypothesis 2 (H2). There are no statistically significant differences between the means of the scores of male and female students in the study variables (of habits of mind, problem-solving skills, and psychological hardiness.

Hypothesis 3 (H3). Isolating problem-solving skills affect the relationship between the habits of mind and the psychological hardiness of university students.

\section{Method}

\subsection{Research Methodology}

The study utilized a descriptive research method, using path analysis to test the validity of hypotheses regarding the relationships between the research variables. It identifies the direct and indirect causal relationships and influences between habits of the mind as an independent variable, problem-solving skills as a mediator variable, and psychological hardiness as a dependent variable.

\subsection{Participants}

A total of 300 (160 female and 140 male) university students were chosen from the third year of all scientific and literal departments, Faculty of Education, Minia University, Egypt (age mean=20.820, SD=0.665) to verify the validity and reliability of the research instruments. While, the basic research sample consisted of (485) male and female students (age mean=20.826, $\mathrm{SD}=0.645$ ).

\subsection{Measures}

\subsubsection{Habits of Mind Scale according to Daniels's 1999 Classification}

After reviewing related literature, studies, and measures accessible in this variable, the habits of mind scale for university students were designed according to Daniels' (1999) four classifications of habits of mind. The scale comprised (40) items distributed into the four classifications: open-minded, fair-minded, independent-minded, and inquiring or critical attitudes, with five alternatives in front of each item. The participant needed to grade their point of view accordingly: ( 5 always - 4 often - 3 sometimes - 2 little - 1 never). The scale was presented in its initial form to seven mental health and psychology professors as arbitrators, to determine the suitability of the statements to measure habits of mind among university students. They agreed on all statements while paraphrasing six statements. 
The researchers examined the scale factorial validity after confirming the appropriateness of the sample and the scale for this statistical method by using Kaiser-Meyer-Olkin (KMO) and Bartletts equations. Through using the Varimax method, factor analysis resulted in (4) factors, where factor load of 35 items was more than $(0.30)$ as follows: the first-factor is open-minded (7) items, the second-factor fair-minded (9) items, the third-factor is independent-minded (9) items and, the fourth factor is inquiring or critical attitude (10) items. Furthermore, five items were omitted because their factor load was under the acceptable level. Thus, the number of scale statements in its final form reached (35) items distributed into the four factors. The overall degree of the scale ranged from (35: 175).

The internal consistency of the scale was calculated and all results revealed that the correlation coefficients were statistically significant at the level of (0.01). To confirm the habits of mind scale reliability, the study utilized the Cronbach's Alpha and the Split-half methods on a sample that consisted of (300) students, from Minia University. The reliability coefficients ranged between $(0.650-0.900)$, and the split-half reliability correlations ranged between (0.578-0.911). Accordingly, the scale achieved high validity and reliability to be applied in the basic study.

\subsubsection{Problem-Solving Skills Scale}

A problem-solving skills scale for the participants was designed as an instrument for achieving the research objectives based on Emuford's classification of three problem-solving skills (ability, competence, coordination) (Bansal, 2018). The scale consisted of (26) statements with five alternatives in front of each statement. The participant needed to grade their point of view accordingly: (5 always - 4 often - 3 sometimes - 2 little - 1 never). The researchers presented the scale in its initial form to seven mental health and psychology professors as arbitrators, to ensure the suitability of the scale statements to measure the three problem-solving skills. They agreed on all the scale statements while modifying the wording of the two statements.

The scale factorial validity was examined after confirming the appropriateness of the sample and the scale for this statistical method by using Kaiser-Meyer-Olkin (KMO) and Bartletts equations. Through using the Varimax method, factor analysis resulted in three factors, where the factor load of 20 items was more than (0.30) as follows: ability with seven items, competence with six items, and coordination with seven items. Furthermore, six items were deleted because their factor load was less than (0.30). Thus, the number of scale statements in its final form was (20) items distributed into the three scale factors. The overall degree of the scale ranged from (20:100).

Internal Consistency of the Scale was confirmed via calculating the correlation of the degree of each item to the dimension to which they belonged to. The correlation of the three problem-solving skills dimensions to the overall degree of the scale was calculated, and all correlation coefficients were statistically significant at the level of (0.01). Furthermore, to confirm the problem-solving skills scale reliability the researchers utilized Cronbach's Alpha and the Split-half reliability. The reliability coefficients ranged from (0.761- 0.878), and the split-half reliability correlations ranged from (0.734-0.886). Consequently, the scale and its dimensions ensure high validity and reliability to be applied in the basic study.

\subsubsection{Psychological Hardiness Scale (Mukhaimar, 1996)}

Mukhaimar's (1996) Psychological hardiness scale is an instrument that estimates an individual's psychological hardiness quantitatively. It is comprised of 47 items that concentrate on dimensions of an individual's psychological hardiness. The score for each item ranged from three to one degree as follows: always apply to me (3), sometimes apply to me (2), and never apply to me (1). That the total degree of the instrument ranged between 47:141 scores. A high score refers to an increased respondent's psychological hardiness awareness. To reduce the fixed pattern of set response, some statements are set in the opposite direction of others. That some inverted expressions indicate the negative side of psychological hardiness, they are as follows: (7-11-16-21-23-25-28-32-35-36-37-38-42-46-47), these statements constitute $31 \%$ of the total item numbers of the scale. These statements degrees are as follows: always apply to me (1), sometimes apply to me (2), and never apply to me (3). The high degree demonstrates the high individual's awareness of his psychological hardiness. The scale falls into three dimensions as follows: commitment, control, and challenge.

The validity of the scale was verified through internal consistency by calculating the correlation coefficient between the scale dimensions together, and between the dimensions of the scale and the overall degree of the scale. All correlation coefficients were significant at the (0.01) level.

In addition, to confirm the scale reliability Cronbach's Alpha and the Split half reliability on the research sample were assigned for verifying the research tools that comprised of (300) third-year Faculty of Education students. The reliability coefficients ranged from (0.574- 0.811), and the split-half reliability correlations ranged between (0.577-0.762). Accordingly, the scale achieves a high validity and reliability that enabled it to be applied in the basic 
study.

\subsection{Analysis Method}

The software statistical analysis SPSS v.25 and AMOS v.24 were used for data analysis whereas t-test, fit indexes, correlation coefficients, and path analysis were utilized to verify the study hypotheses.

\section{Results}

3.1 The First Hypothesis Results: "There is A Fit of the Proposed Structural Model for Problem-Solving Skills as A Mediator Variable between Habits of Mind as An Independent Variable and Psychological Hardiness as A Dependent Variable among University Students"

To verify the validity of this hypothesis path, analysis through Maximum Likelihood Estimation to find out the effect of problem-solving skills on habits of mind and psychological hardiness as a mediator variable were used. A causal model based on a theoretical basis through reviewing literature and related studies was established, as it was the most appropriate model for the research topic. The structural equation model analysis was then conducted to ensure the proposed model's good fitness to the data presented in the current study. Through using the path analysis method in AMOS 24 program, according to some statistical indicators, there were high correlations between these variables which guided the model design. The researchers followed these procedures: building a causal model among variables of the current study, establishing a pattern that represents the relationship between variables respectively, drawing a schematic model for the path of relationships between variables, calculating path coefficients, testing the goodness of fit index, analyzing and interpreting results.

The main hypothesis was validated and the path analysis model obtained good fit indexes, as $\chi 2$ was not significant, and the values of the rest indexes were in the acceptable threshold levels, which indicates the good fit of data to the model. These indexes were chosen as they were less dependent on the sample. Figure 2 below illustrates the habits of mind variable as an independent variable, problem-solving skills as an intermediate variable, and psychological rigidity as a dependent variable formed a constructive model that explains the causal relationships (effects) between these variables in the current article sample.

Figure 2 represents the final statistical model for path analysis between the article variables.

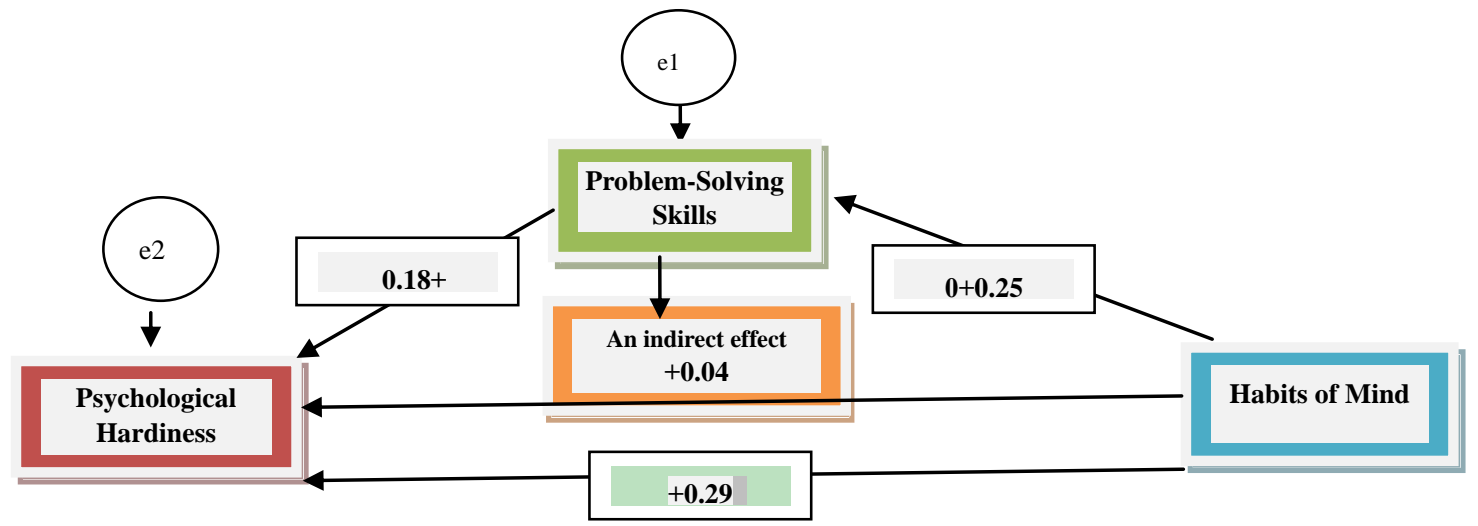

Figure 2. The statistical model for path analysis between problem-solving skills as a mediator variable between habits of mind and psychological hardiness

The results of the first hypothesis can be interpreted within Costa \& Kallick's (2009) definition that habits of mind are a group of cognitive constructs that constitute part of the individual's cognitive construction, which the individual utilizes in various situations to find out solutions to problems or to recall the appropriate behavior for a certain situation. Furthermore, habits of the mind are necessary for effective thinking for those individuals who have the before-mentioned habits of not just think deeply, but also solve problems when needed through their mental abilities. Habits of mind also reflect a pattern of smart performances that may lead students to productive action. These actions are usually formed as a result of the individual's response to certain types of problems and issues, provided that solutions to such problems require thinking, research, and reflection, as solving problems requires mental strategies, deep insight, perseverance, and creativity in solving the problems.

This result demonstrates that psychological hardiness contributes to an individual's mental and physical well-being when confronted by pressures, as it reinforces their ability to negotiate pressures and overcome them. Psychological hardiness plays a mediator role between the individual's cognitive assessment of stressful experiences and 
preparation for adaptive responses. Such mechanisms reduce the level of psychological stress effectively. More specifically, individuals exhibiting highly psychological hardiness are characterized by their ability to engage with problems, as they consider problems as normal and not threatening, and they anticipate and prepare for problems, and this is consistent with the findings of (Abbas, 2010; Maddi, 1999).

\subsubsection{The First and Second Sub-Hypotheses Results}

"There is a direct statistically significant effect of habits of mind on psychological hardiness among university students and there is an indirect statistically significant effect of habits of mind on psychological hardiness through problem-solving skills as a mediator variable for university students", results revealed the verification of these two sub-hypotheses. The first sub-hypothesis can be discussed in the light of Daniels' (1999) perspective of habits of mind, which illustrated that these habits logically correspond to the characteristics of students with high psychological hardiness, as mental interdependence means the ability of the individuals to self-efficiency, lack of dependence on others in his way of thinking, and that their ideas are characterized by cognitive flexibility, which helps him in facing stressful situations and solving problems with flexibility and stability. This was demonstrated by various study results that indicated the relationship between habits of mind and the ability to cope with stressful situations, as those with high psychological hardiness characterize by the ability to endure, resist and face stress (Amin\& Gaber, 2018; Kleinsteuber, 2014). Psychological hardiness is also positively associated with mental alertness, relicense, mental and psychological health (Kowalski\& Schermer, 2019) and they are logical indicators of independent-minded and inquiring or critical attitude dimensions.

The second sub hypothesis can be interpreted due to the fact that one of the habits of mind component (independent-minded) had a significant indirect positive effect on the dependent variable (psychological hardiness) through the mediating variable (competence) as one of the problem-solving skills. As habits of mind are strategies that enable the individual to solve the problem, no matter how difficult it is, through smart behavior when the individual does not have a solution, which is what we can call (efficiency) (Joicevan \& Tamara, 2006). They are also some skills and values that enable the individual the freedom to choose among the options available to confront a problem, which we call (mental independence), they are patterns of constant and continuous mental performance to reach a rational behavior to confront situations and solve problems (Costa \& Kallick, 2000; 2009). Additionally, mental independence includes taking responsibility and the ability to make decisions, which are behaviors that contribute to facing stressful situations and developing psychological toughness, and this is in line with Campbell's study (Campbell, 2006).

\subsubsection{The Third Sub-Hypothesis Result}

Results indicate the verification of the previous sub-hypothesis and the existence of a statistically significant positive direct effect on the habits of the mind on problem-solving skills. The third sub-hypothesis results are consistent with various study results which concluded that there is a relationship between the habits of the mind and the ability to solve problems and that the ability to solve problems can be predicted through the individual's habits of the mind (Al-Fastala \& Abu Asaad, 2015; BİLGİÇ, 2018; Virginia, 2015). Researchers support this result because people with high habits of mind, according to Daniels' (1999) model possess a strong personality during decision-making and problem-solving. Mental openness helps students to extend their perceptions and think flexibly while making decisions, balance all proposed ideas to choose the best ones, and recognize the strengths and weaknesses of any issue to evaluate them, and thus these habits contribute to developing students' skills to solve their problems in a good way.

\subsubsection{The Fourth Sub-Hypothesis Result}

Results indicate the verification of this sub-hypothesis and that there was a statistically significant positive direct effect of problem-solving skills on psychological hardiness among university students. This may be explained by e researchers explain this result as students with (ability) as one of the of problem-solving skill have the attitude to continue solving problems during difficult situations, and they are characterized by the ability to discover various alternatives to solve problems and challenges to face stressful situations, and this contributes to the development of their psychological hardiness. This is confirmed by Hosseinian \& Beh-Pajooh's (2018) research results which demonstrated that there was an effect on psychological hardiness through problem-solving skills, and that psychological hardiness mediated the relationship between problem-solving skills and suicidal thinking (Muhammad et al., 2018). 
3.2 The Second Hypothesis Validation Results: "There are No Statistically Significant Differences between the Means of the Scores of Male and Female Students in the Study Variables (Habits of Mind, Problem-Solving Skills, and Psychological Hardiness)"

To validate this hypothesis, a t-test was utilized and the following table indicated the results:

Table 1. Arithmetic Mean, Standard Deviation, (t) value and Its Significance for the Differences between the Mean Scores of Males and Females in the study variables $(n=485)$

\begin{tabular}{lllllll}
\hline Variables & \multicolumn{2}{l}{ Males $(\mathbf{n}=\mathbf{2 1 2})$} & \multicolumn{2}{l}{ Females=273) } & & \\
& Mean & Std. Deviation & Mean & Std. Deviation & t-value & Sig. \\
\hline Habits of Mind & 132.542 & 15.262 & 132.040 & 15.338 & 0.358 & not significant \\
Problem-Solving Skills & 79.641 & 8.968 & 78.421 & 10.554 & 1.347 & not significant \\
Psychological Hardiness & 108.094 & 9.760 & 106.699 & 9.137 & 1.618 & not significant
\end{tabular}

Table 1 clarified that there were no significant differences between the two genders in the study variables (habits of mind, problem-solving skills, and psychological hardiness). These results are consistent with El-Noab \& Hussein's (2013) study and differ from the results of Al-Assaf (2017), Muhammad (2015), and Abo Latifa (2019) studies which indicated that there are differences between males and females in habits of the mind. This result can be explained by the fact that male and female students at the university live have the same educational environment, and are exposed to the same activities and tasks as well as the same academic conditions and experiences. Furthermore, other researchers (El Jalba et al., 2018; El-Noab \& Hussein, 2013) explained that habits of the mind are intelligent intellectual behaviors that students learn through their acquisition through the availability of a rich stimuli environment, and it is not limited to a certain group, segment, or age. Accordingly, any male or female student can possess the desire for these habits, and the cultural, social, and educational institutions are the same for both genders.

Concerning problem-solving skills, this result is consistent with the study of Yenice (2011) and differs from Sagir and Uluicinar's (2016) study which indicated the existence of gender differences in problem-solving skills. This result can be explained by the university education pattern, strategies, and methods, as well as the available opportunities for self-education, access to references, communication with colleagues, discussion, and dialogue. Thus, male and female students share all these factors that in role leads to the development of their problem-solving skills to encounter any academic and social problems and difficulties.

The results of psychological hardiness are consistent with the study of Al-Tala and El-Wakeel's (2015) results and differ from Shaqqura and Olayan's (2012) study that demonstrates the differences between genders in psychological hardiness. This result can be explained by the students' living conditions, as they grew up in the same conditions and are still living in. Nevertheless, students at this stage share the same difficulties which require similar strategies and methods to solve problems and adapt solutions.

3.3 The Third Hypothesis Validation Results: "Isolating Problem-Solving Skills Affect the Relationship between the Habits of Mind and Psychological Hardiness of University Students"

To verify this hypothesis; the simple and partial correlation coefficients were calculated after isolating the effect of problem-solving skills. Results revealed that there was a statistically significant positive direct correlation coefficient between habits of mind and psychological hardiness. The correlation coefficient was (0.583), which is significant at (0.01) significance level. When isolating the effect of problem-solving skills from the relationship between habits of mind and psychological hardiness, the value of the correlation coefficient between habits of mind and psychological hardiness decreased, but it still had a significant coefficient. Also, the partial correlation coefficient was (0.641), which is statistically significant at (0.01) significance level. Thus, it can be stated that problem-solving skills partially mediates the relationship between habits of mind and psychological hardiness. Thus the hypothesis is accepted. This result is consistent with Daniels' (1999) perspective who stated that the open-minded, fair-minded, the independent-minded persons and those with inquiring and critical attitudes characterize by strong and dynamic personalities, can communicate and negotiate with others, help others, enjoy flexible thinking depend on previous experiences, can solve their problems creatively, can differentiate between different solutions and choose the most appropriate, can criticize ideas to select (Daniels, 1994). These habits are consistent with the characteristics of students with high psychological hardiness (Taylor, 1995; Van \& Bos, 2006).

\section{Discussion}

The main purpose of this article was to investigate the role of problem-solving skills as a mediator variable in the 
relationships between university students' habits of mind, and the psychological hardiness and designing a structural model for this relationship. This topic has not been previously studied in the Egyptian context, and despite the existence of several international studies that focused on such variables and providing the existence of such a relationship, research about mediator is sparse. The results of this study are expected to represent a relevant contribution to understand this issue and contribute to the development of other studies in this field.

Clarifying the relationship between the variables under study was extremely important to be implemented and improved in universities to prepare students for modern requirements. The results of the current research resulted in a good match of the proposed model with the data of the participants in the research, and the presence of statistically significant correlations between the research variables, and there are no significant differences between males and females in the research variables (habits of mind, problem-solving skills, psychological rigidity), and mediation Partially problem-solving skills between habits of the mind as an independent variable and psychological toughness as a dependent variable among university students. And it is It was not possible to generalize the current result through the proposed model except after these variables were made with other categories of male and female students in different educational stages.

To confirm the causal relationships and the direct and indirect effects of the variables of the current research, future directions recommend making use of the proposed model by building educational programs and strategies based on the habits of the mind to develop problem-solving skills and psychological hardiness, and to benefit from the results of the current research in directing university planning officials to enrich academic courses in a way that supports habits of mind and psychological rigidity and develop their problem-solving skills.

\section{Acknowledgment}

We would like to thank all students participating in the study, and the Deanship of Scientific Research at Prince Sattam bin Abdul-Aziz University, Alkharj, Saudi Arabia.

\section{References}

Abbas, M. (2010). Psychological hardiness as a predictor to reducing stress and aggressive behavior among middle school teachers. Faculty of Education Journal, Assuit University, 26, 167-236.

Abdollahi, A., Talib M., Yaacob, S., \& Ismail, Z. (2015). Problem-Solving Skills Appraisal Mediates Hardiness and Suicidal Ideation Among Malaysian Undergraduate Students. PLOS ONE, 10, 1-14. https://doi.org/10.1371/journal.pone.0122222

Abo Latifa, L. (2019). Habits of mind among graduate students in the College of Education at Al-Baha University. Rafad Center for Studies and Research, 5, 279-296.

Abo Shaban, N. (2010). The effect of using peer teaching strategy on developing critical thinking skills in mathematics among eleventh-grade students, Department of Human Sciences (Literal Discipline). Doctoral Dissertation, Faculty of Education, Islamic University of Gaza.

Al-Adl, A., \& Abdel Wahab, S. (2003). The ability to solve problems and the metacognitive skills of the ordinary and the intellectually superior. Journal of the Faculty of Education, Ain Shams University, 3, 181-258.

Al-Assaf, J. (2017). The Teaching Habits of Mind, Their Relationship to Positive Behavior of Social Studies Teachers in Lower Basic Stage in University District - The Capital (Amman). Journal of Curriculum and Teaching, 6(1), 30-51. https://doi.org/10.5430/jct.v6n2p30

Al-Ayasrah, W. (2015). Teaching strategies and thinking skills; Amman: Osama House for Publishing and Distribution.

Al-Fastala, R., \& Abu Asaad, A. (2015). Habits of mind and its relationship to the problem-solving ability of outstanding students in King Abdullah II Schools of Excellence in the Hashemite Kingdom of Jordan. Master Thesis, Mu'tah University, Karak.

Al-Hadari, S. (2018). The meaning of life and its relationship to psychological hardiness and a sense of hope among a sample of visually impaired adolescents. International Journal of Educational and Psychological Sciences, Arab Foundation for Scientific Research and Human Development, 14(10), 85-161.

Al-Harthi, I. (2002). Habits of Mind and their development among students. Riyadh: Al-Shaqry Library.

Al-Helou, M. (2001). Educational psychology a contemporary view. Gaza, Dar Al-Miqdad for printing.

Al-Otaibi, K. (2007). The effect of using some parts of the Kort program (expanding the field of perception and 
interaction) to find out its impact on developing critical thinking skills and improving academic achievement among a sample of high school students in Riyadh. Doctoral Dissertation, College of Education, Umm Al-Qura University.

Al-Quraishi, M. (2014). Lateral thinking and problem-solving skills among students of distinguished and ordinary schools. Journal of the Center for Kufa Studies, University of Kufa, 9(1), 308-381.

Al-Tala'a, M. (2016). Spiritual intelligence and its relationship with psychological hardiness among students of the Islamic University of Gaza. Master Dissertation, Islamic University of Gaza.

Altum, A., \& Cakan, M. (2006). Undergraduate students' academic achievement, field-dependent/independent cognitive styles, and attitude toward the computer. Educational Technology \& Society, 9(1), 289-297.

Amin, I., \& Gaber, G. (2018). Habits of mind and its relationship to professional stresses among kindergarten teachers. Childhood and Education Journal, Alexandria University, Kindergarten College, 10, 97-132.

Amlakian, P., \& Amiri, M. (2020). Taheri, E. The mediating role of psychological hardiness in the relationship between spiritual wellbeing and religious commitment with the vitality in people with substance abuse disorder. Journal of Fundamentals of Mental Health, 22(10), 21-30.

Bansal, P. (2014). Effects of experiential learning strategies on problem solving ability of adolescents from psychological hardiness perspective, Indian Journal of Health and Wellbeing, 5(5), 574-578.

Bartone, T. (2007). Harnessing hardiness - psychological resilience in persons and organizations. Industrial College of the Armed Forces National Defense University Washington, DC, USA college students. Social Behavior and personality, 26(1), 51-56.

BİLGİÇ, E. (2018). Investigation of Mathematical Mind Habits of Preservice Elementary Mathematics Teacher in Problem Solving, Necatibey Faculty of Education Electronic. Journal of Science and Mathematics Education, 12(1), 63-82. https://doi.org/10.17522/balikesirnef.437659

Campbell, J. (2006). Theorising habits of mind as a framework for learning. Computer and Mathematics Science, 6, 102-109.

Cormier, D. C., Yeo, S., Christ, T. J., Offrey, L. D., \& Pratt, K. (2016). An examination of the relationship between computation, problem solving and reading. Exceptionality, 24(4), 225-240. https://doi.org/10.1080/09362835.2015.1064418

Costa, A. L., \& Kallick, B. (2009). Habits of mind across the curriculum: Practical and creative strategies for teachers. ASCD.

Daniels, R. (1994). Motivational mediators of cooperative learning. Psychological Reports, 74(3), 1011-1022. https://doi.org/10.2466/pr0.1994.74.3.1011

De, Raad, B., \& Perugini, M. (2002). Big Five Assessment: Preface. Hogrefe \& Huber Publisher.

Delahaij, R., Gaillard, A., \& van Dam, K. (2010) Hardiness and the response to stressful situations: Investigating mediating processes. Personality and Individual Differences, 49, 386-390. https://doi.org/10.1016/j.paid.2010.04.002

Eid, M. (2002). Identity, anxiety, and creativity. Cairo: Cairo House.

El Jalba, W., Soliman, S., \& Yousef, M. (2018). The effectiveness of a program to develop the psychological resilience of the university student to improve methods of coping with stressful life events. Journal of Scientific Research in Education, Ain Shams University, 19, 2013-253.

El Khawlani, M. (2014). The effectiveness of a computer program based on the theory of creative solutions to mathematical problems (TRES) in developing the habits of mind and teaching performance for middle school mathematics teachers. Doctoral Dissertation, Faculty of Education, Damietta University.

El-Noab, N., \& Hussein, M. (2013). Habits of mind and higher-order thinking and their relationship to self-efficacy among students of colleges of education. Journal of Human Sciences, University of Babylon, College of Education for Humanities, 19, 149-172.

El-Wakeel, H. (2015). Some predictors of psychological resilience among a sample of university students. Master Thesis, Menoufia University, Egypt.

Emuford, S. (2002). Effectiveness of Solving Problems Collaboratively On Students' Ability to Solve the Problem 
Individually Style. Journal of Educational, 4, 82-129. https://doi.org/10.5206/cjsotl-rcacea.2015.3.10

Gail, V. (2006). Teacher research as a habit of mind. Master Dissertation, Gorge Mason of University.

Haiman, S. (2009). A revised scale for the measurement of open-mindedness. Journal Speech Monographs, 31(2), 97-102. https://doi.org/10.1080/03637756409375396

Hansen, J. (1995). Student cognitive styles in postsecondary technology programs. Journal of Technology Education, 6(2), 19-28. https://doi.org/10.21061/jte.v6i2.a.2

Hosseinian, A., \& Beh-Pajooh, A. (2018). The Moderating Effect of Hardiness on the Relationships between Problem-Solving Skills and Perceived Stress with Suicidal Ideation in Nursing Students. Studia Psychologica, 60(1), 30-41. https://doi.org/10.21909/sp.2018.01.750

Joicevan, T., \& Tamara, S. (2006). Habits of mind and creative thinking. Long Man Inc, New York.

Kleinsteuber, A. (2014). The impact of professional development in the arts upon habits of mind and teacher efficacy. Doctoral Dissertation, California State University.

Kobasa. S., Maddi, S., Paccetti, C., \& Zola, M. (1985). Effectiveness of hardiness, exercise and social support as Resources against illness, Journal of Psychometric Research, 29(5), 525-533. https://doi.org/10.1016/0022-3999(85)90086-8

Kowalski, C., \& Schermer, J. (2019). Hardiness, Perseverative Cognition, Anxiety, and Health-Related Outcomes: A Case for and Against Psychological Hardiness. Psychological Reports, 122(6), 2096-2118. https://doi.org/10.1177/0033294118800444

Lambert, A., Lambert, E., \& Yamase, H. (2003). Psychological hardiness, Workplace, and related stress reduction strategies, Journal of nursing and health sciences, 5(2), 181-184. https://doi.org/10.1046/j.1442-2018.2003.00150.x

Maddi, S. (1999). The personality construct of hardiness: Effects on experiencing, coping, and strain. Consulting Psychology Journal: Practice \& Research, 51, 83-94. https://doi.org/10.1037/1061-4087.51.2.83

Maddi, S. (2006). Hardiness: The courage to grow from stress. The Journal of Positive Psychology, 1(3), 160-168. https://doi.org/10.1080/17439760600619609

Muhammad, A. (2015). The psychological resilience of the displaced and non-displaced university students. Journal of Arts, University of Baghdad, 114, 603-626.

Muhammad, A., Sulaiman, S., \& Al-Shaarawi, S. (2018). Marital compatibility and its relationship to psychological hardiness, empathy, and coping strategies among university students. Journal of Scientific Research in Education, Ain Shams University, 6 (11), 89-116.

Mukhaimer, I. (1996). Psychological Hardness Scale. Cairo: The Egyptian Renaissance Library.

Muslim, I. (1993). New in teaching methods. Amman: Publishing House for Printing.

Perkins, D., Costa, A. L., Kallick, B., \& Hyerle, D. (2000). Activating and engaging habits of mind. Alexandria, VA: The Association for Supervision and Curriculum Development.

Sagir, A., \& Safek, U. (2016). Research in problem solving skills of the teacher candidate. Journal of new world sciences academy (NWSA), 6(2), 2482-2494.

Shaqqura, Y., \& Alian, M. (2012). Psychological resilience and its relationship to contentment with life among PirOalestinian university students in Gaza governorates. Master Thesis, Al-Azhar University, Gaza.

Shatta, A. (2015). Critical thinking and its relationship to academic adjustment. Master Thesis, Faculty of Humanities and Social Sciences, Qasidi Merbah and Ouargla University.

Shind, M., Al-Saadi, A., \& Ibrahim, H. (2015). Psychometric properties of the psychological Hardness Scale. Journal of Psychological Counseling, Ain Shams University, 44, 445-462.

Tatari, F., Farnia, V., Momeni, K., Davarinejad, O., Salemi, S., Soltani, B., ... \& Alikhani, M. (2020). Predicting addiction potential based on sensation-seeking, psychological hardiness and assertiveness in students in western Iran: an analytical study. Journal of Substance Use, 1-6. https://doi.org/10.1080/14659891.2020.1760371

Taylor, S. (1995). An Analysis of a Relaxation Stress Control Program in an Alternative Elementary School. Dissertation Abstracts International, 35, 169-210. https://doi.org/10.1177/004005999002200407 
Van, A., \& Bos, C. (2006). I Plan: Helping Students Communicate in Planning conferences. Teaching Exceptional Children, 22, 30-32. https://doi.org/10.1177/004005999002200407

Virginia R. (2015). Habits of Mind: Problem solving. Child's Technology and Engineering, 19, 2, 1-40.

Yenice, N. (2011). Investigating pre-service since teachers' critical thinking disposition and problem solving variables. Educational Research and Reviews, 6, 497-508.

Zaitoun, H. (2003). Teaching Thinking an Applied Vision in the Development of Thinking Minds. Pedagogy of education series, Cairo: The World of Books.

\section{Copyrights}

Copyright for this article is retained by the author(s), with first publication rights granted to the journal.

This is an open-access article distributed under the terms and conditions of the Creative Commons Attribution license (http://creativecommons.org/licenses/by/4.0/). 